\title{
O uso da computação desplugada em um contexto de gamificação para o ensino de estrutura de dados
}

\author{
Jussara Adolfo Moreira - IF Sertão Pernambucano Campus Petrolina - \\ jussara.moreira@ifsertao-pe.edu.br \\ Willmara Marques Monteiro - IF Sertão Pernambucano Campus Petrolina - \\ willmaramarques@gmail.com
}

Resumo: Nos dias atuais se faz ainda mais necessário o uso de novas metodologias para que a aprendizagem dos alunos se torne mais significativa. Estamos diante de uma geração rodeada por tecnologias e que constrói o seu aprendizado de maneira diferenciada. Este artigo tem por objetivo apresentar um relato de experiência na reformulação da disciplina Estrutura de Dados em um curso de computação, usando gamificação e computação desplugada para motivar e simplificar conceitos, para obter aprendizagem significativa. Os resultados apontam que o uso de tais metodologias proporcionou melhorias no aprendizado dos alunos. Conclui-se que o uso de tais métodos de ensino é essencial para atrair a atenção dos discentes e ainda criar estratégias para o ensino de conteúdos considerados complexos, como linguagens de programação

Palavras-chave: gamificação. computação desplugada. estrutura de dados.

\section{The usage of unplugged computation in a gamification context to the learnship of data estructure}

Abstract: Nowadays it is way more necessary the usage of new methodology so that the apprenticeship of students became more significantly. We're facing a generation surrounded by technology and builds it's learning distinguishly. This article has as goal present an experience report in the reformulation of the discipline Estrutura de Dados in a computation upper course, using gamification and unplugged computation to motivate and simplify concepts, so it can obtain significantly learnship. The results indicates that the usage of such methodologies has provided improvementes in the students learning. Concluding, the usage of such teaching methods is essential to attract the attention of students and yet, create strategies to the education of contents that were considerated complex, such as programming languages.

Keywords: gamification. unplugged computation. data estructure.

\section{INTRODUÇÃO}

Experiências que envolvem o ensino de programação no Brasil vêm crescendo nos últimos anos. Diversas pesquisas têm mostrado resultados de intervenções realizadas em vários níveis de escolaridade. Destaca-se que o ensino de programação é um conteúdo fundamental nos cursos de computação, o assunto requer dedicação e motivação para existir uma aprendizagem significativa.

Publicações científicas apontam que existem grandes dificuldades do ensino da programação nos cursos de ensino superior, conforme citado por Barbosa (2011) e Correia (2015). Esses estudos, ainda, apontam dados alarmantes sobre a evasão dos cursos de Computação. As componentes curriculares que possuem como conteúdo programação são as que causam maior desistência por parte dos alunos. Para construir 
bons programas é necessário saber pensar computacionalmente, o que não é um sinônimo de "programar". Segundo Andrade et al. (2013), o Pensamento Computacional se utiliza de atividades que introduzem os conceitos de coleta, análise e representação de dados, decomposição de problemas, simulação, automação, algoritmos, paralelismo e abstração, sem o uso de computadores. Muitos conceitos são importantes de serem entendidos para que possam ser utilizados adequadamente. Além dos conceitos iniciais a motivação e interesse afetam diretamente o desempenho do estudante, com consequências explícitas no processo de aprendizagem.

Já gamificação tem por princípios aplicar aspectos do design de games, ao processo de ensino aprendizagem, e assim motivar o aluno a estar engajado durante a disciplina. Em outras palavras, um dos objetivos dessa metodologia é motivar, proporcionar um ambiente de aprendizagem mais significativo e atraente (Fardo, 2013). Já a computação desplugada se destaca como o ensino de fundamentos da Ciência da Computação, sem a necessidade de computadores, através de atividades desplugadas (Bell, et al., 2009).

Dessa maneira, o objetivo desse artigo é relatar uma experiência realizada utilizando a gamificação e a computação desplugada para ensinar o conteúdo de Estrutura de Dados no curso superior de Licenciatura em Computação do Instituto Federal de Ciência e Tecnologia do Sertão Pernambucano (Campus Petrolina).

\section{GAMIFICAÇÃO E COMPUTAÇÃO DESPLUGADA}

Uma das metodologias mais disseminada na atualidade é a gamificação. Trata-se de um fenômeno emergente, que surgiu da popularidade dos games e o potencial dos mesmos para ensinar. Koivisto e Hamari (2014) definiram a gamificação como um fenômeno, cuja proposta é proporcionar uma experiência de jogo. Em outras palavras, a gamificação faz o uso de elementos de jogos em contextos de não jogo, por exemplo, a sala de aula.

A gamificação teve seu surgimento em programas de marketing, em empresas e sua principal finalidade é motivar, engajar pessoas na realização de atividades, desafios (Zichermann; Cunningham, 2012). Essa metodologia faz o uso de elementos que são próprios dos games: narrativa, sistema de feedback, sistema de recompensas, regras, níveis, tentativa e erro, diversão, entre outros.

$\mathrm{Na}$ educação, a gamificação encontra um terreno fértil para sua aplicação (Fardo, 2013). É uma nova estratégia para atender a necessidade de indivíduos que estão cada vez estão mais inseridos no contexto das mídias e das tecnologias digitais. Essa nova geração já não se mostra atraída pelos métodos "tradicionais" de ensino e aprendizagem utilizados na maioria das escolas.

A gamificação pode ser utilizada em diversas áreas do ensino. Há relatos do seu uso no ensino de Ciências (Rouse, 2013), Matemática (Goehle, 2013) entre outros. Uma outra área que a gamificação pode ser aplicada é a computação, o uso dessa metodologia é relatado por Li et al. (2013) que usaram essa metodologia para ensinar Ciência da Computação para crianças. Essa experiência aumentou o engajamento dos alunos nas atividades propostas.

Já o conceito de computação desplugada cunhado por Bell et al. (2009) vai ao encontro do conceito "Computational Thinking" (Pensamento Computacional) criado por Wing (2006). Ambos defendem o uso de conceitos da ciência da computação para a resolução de problemas ditos como reais, ou seja, com real aplicação no cotidiano.

Segundo Bell et al. (2009) as atividades desplugadas envolvem a resolução de problemas para alcançar um objetivo e ainda auxiliam na compreensão de conceitos fundamentais de Ciência da Computação. 
De acordo com os autores do livro Computer Science Unplugged, o material foi construído visando suprir as dificuldades encontradas no ensino da computação (Bell, et $a l, 2009)$. Outro ponto a ser destacado sobre a metodologia Computação Desplugada é que a mesma pode ser aplicada não somente para crianças, mas para todas faixas etárias, desde o ensino fundamental até o ensino superior, proporcionando dessa maneira, diferentes conhecimentos e experiências.

\section{ORGANIZAÇÃO DA DISCIPLINA}

A disciplina Estrutura de dados (ED) tem carga horária de 60 horas, divididas entre 30 horas práticas e 30 teóricas. A disciplina foi dividida em duas unidades e em cada uma foram realizadas duas avaliações: uma com a pontuação das atividades, gamificadas e desplugadas e outra com avaliação tradicional. As notas foram somadas e divididas por dois para obter a nota de cada unidade. A utilização de elementos de jogos e computação desplugada procurou oferecer um contexto mais adequado e significativo, dado o perfil dos estudantes: entre 18 e 25 anos, que possui afinidade por jogos. Sobre o conteúdo da disciplina, o mesmo está organizado da seguinte maneira: Unidade 1 (Recursividade, Filas e Pilhas) e Unidade 2 (Listas, Estruturas contíguas $e$ encadeadas, Árvores e suas aplicações).

$\mathrm{O}$ princípio da recursividade consiste em diminuir sucessivamente o problema em um problema menor até que a simplicidade do problema permita resolvê-lo, ser lido ou escrito por um programa, sendo constituído por uma coleção de caracteres (arquivo texto) ou bytes (arquivo binário) (Ascencio, 2010).

A estrutura denominada fila é considerada do tipo FIFO (Firt In Fist Out), ou seja, o primeiro elemento inserido será o primeiro a ser removido. As seguintes operações podem ser realizadas nesse tipo de estrutura: inserir na fila, consultar toda a fila, remover e esvaziá-la.

A estrutura denominada pilha é considerada do tipo FILO (Firt In Last Out), ou seja, o primeiro elemento inserido será o último a ser removido. Nessa estrutura, cada elemento armazena um ou vários dados e um ponteiro para o próximo elemento, permitindo o encadeamento e mantendo a estrutura linear (Ascencio, 2010). As seguintes operações podem ser realizadas nesse tipo de estrutura: inserir na pilha, consultar toda a pilha, remover e esvaziá-la.

As listas são estruturas formadas por um conjunto de dados de forma a preservar a relação de ordem linear entre eles. Cada elemento é inserido em uma posição de um vetor, por exemplo, inicialmente na posição zero, posteriormente cada elemento deve ser inserido conforme ordenação. (Ascencio, 2010)

Em uma lista encadeada, segundo Ascencio (2010) cada elemento armazena um ou vários dados e possui um ponteiro para o próximo elemento, que permite $\mathrm{o}$ encadeamento e mantém a estrutura linear. As seguintes operações podem ser realizadas nesse tipo de estrutura: inserir no início da lista, inserir no fim, consultar toda a lista, remover um elemento qualquer dela e esvaziá-la. Já, segundo Ascencio (2010), uma árvore binária é um conjunto finito de elementos, onde cada elemento é denominado nó e o primeiro é conhecido como raiz da árvore. Uma árvore é considerada binária quando um nó possui entre zero a dois nós filhos.

\section{A GAMIFICAÇÃO NA DISCIPLINA}

Uma das etapas desse trabalho foi a gamificação da disciplina. Esse processo foi feito da seguinte forma: os alunos iniciaram a disciplina com a média 7 que é o valor mínimo que estudante deve tirar em uma avaliação. Essa pontuação poderia diminuir ou 
aumentar dependendo do desenvolvimento do aluno durante o semestre. Esse formato é similar ao dos games, pois nestes o jogador pode ganhar ou perder "pontos de vida". Cada conteúdo da disciplina foi definido como uma fase, dentro de cada uma havia uma missão (atividades relacionadas a disciplina) contendo desafios que o aluno deveria resolver. Na Tabela 1 podem ser visualizados as fases e objetivos de cada missão e a recompensa/pontuação de cada uma:

Tabela 1 - Gamificação na disciplina

\begin{tabular}{|c|c|c|}
\hline Fases & Missão & Recompensa \\
\hline $\begin{array}{c}\text { Fase 1 - } \\
\text { Recursividade }\end{array}$ & $\begin{array}{c}\text { Criar atividade desplugada para ensino de } \\
\text { recursividade }\end{array}$ & 3,0 pontos \\
\hline Fase 2 - Filas & Criar um jogo usando as regras de uma Fila & 3,5 pontos \\
\hline Fase 3 - Pilha & $\begin{array}{c}\text { Identificar e demonstrar o uso de uma pilha } \\
\text { em soluções para problemas cotidianos }\end{array}$ & 3,5 pontos \\
\hline \multicolumn{3}{|c|}{ Soma total das fases 1, 2 e 3=10 } \\
\hline Fases & $\begin{array}{c}\text { Elaborar um jogo usando listas no } \\
\text { computador ou com comandos em forma } \\
\text { de blocos em EVA ou papel cartonado }\end{array}$ & Recompensa \\
\hline $\begin{array}{c}\text { Fase 4 - Listas } \\
\text { Criar uma atividade de computação } \\
\text { encadeada } 5 \text { - Lista }\end{array}$ & 3,5 pontos \\
\hline $\begin{array}{c}\text { Fase 6 - Árvore e } \\
\text { suas aplicações }\end{array}$ & \begin{tabular}{c} 
Criar árvore de decisão de forma criativa \\
\hline
\end{tabular} & Soma total das fases 4, 5 e 6 $\mathbf{1 0}$ \\
\hline
\end{tabular}

Fonte: Autoras

As fases 1, 2 e 3 correspondem aos conteúdos vistos na primeira unidade da disciplina. A soma total dessas fases resultaria em 10 pontos. As fases 4,5 e 6 estão relacionadas aos conteúdos da segunda unidade. A soma total dessas fases resultaria em 10 pontos. Às atividades das missões correspondiam a $50 \%$ da avaliação de cada unidade. A cada fase os alunos poderiam acumular ou perder pontos. Caso atingissem uma nota maior ou menor que $7 \mathrm{em}$ cada unidade, as notas que possuíam no início do jogo seriam substituídas. A não realização das atividades e a recorrência das faltas faziam com que o aluno perdesse pontos (vidas), e consequentemente seria reprovado.

\section{ATIVIDADES DE COMPUTAÇÃO DESPLUGADA NO ENSINO DE ESTRUTURA DE DADOS}

As atividades usando computação desplugada foram divididas em duas unidades, cada uma relacionada com os conteúdos a serem ministrados. O objetivo dessas atividades era melhorar a compreensão de alguns conceitos da disciplina que são considerados complexos por grande parte dos alunos.

A atividade desplugada para contextualizar o conteúdo recursividade representou o cálculo do fatorial de um número. Foi simulada uma escada em sala de aula, onde cada degrau (feito com emborrachado em EVA) existia um problema $\mathrm{x}$ solução a ser resolvida. O degrau inicial posição inicial (zero), apresentou o problema: 
"Qual o valor do fatorial de 5?", para encontrar a solução é necessário subir um degrau pois o valor do fatorial deste número subtraído de um seria encontrado a seguir. Os alunos puderam perceber que a chamada de uma função recursiva, requer a chamada da mesma função, ao subir o degrau, a ação ilustra a chamada recursiva, ao encontrar um resultado, é possível perceber o retorno (descer degrau), o que é necessário existir para demonstrar o retorno de cada chamada da função.

Já para simular o conceito de Fila a sala foi organizada em um círculo e com uma fila de cadeiras no centro, em cada cadeira foi colocado o índice do vetor. Apenas seis alunos da turma participaram da fila, caso fosse necessário inserir mais alguém, não seria possível pois a fila estaria cheia. Em um copo foi colocado o nome de todos os alunos, e em outro copo os comandos a serem realizados: Enqueиe (Insere), Dequeиe (remove), início (informa a posição inicial), fim (informa a posição final), vazia (informa se a fila está vazia). Os 6 primeiros nomes sorteados participam da fila. Os outros alunos ficaram no círculo e passam o outro copo que possui os comandos a serem realizados, cada aluno deve implementar o comando na fila, e responder o valor do comando. Ao sair da fila cada aluno era bonificado com um chocolate.

A estrutura do tipo pilha possui um ponteiro denominado topo, no qual todas as operações de inserção e remoção acontecem. Dessa forma o último elemento que entra é exatamente o primeiro que sai. Para ilustrar essa estrutura de dados a turma foi dividida em equipes, foi entregue 10 pratos e copos a cada grupo. A professora determinaria os comandos: push (empilha), pop (desempilha), base (informa a base da pilha), topo (informar o elemento do topo da pilha, no caso quantidade de elementos), caso a pilha ficasse cheia a equipe deveria informar overflow e caso ficasse vazia informar underflow. A professora deveria ditar uma sequência de comandos para às equipes poderem realizar a dinâmica. A equipe que tivesse um melhor empenho seria bonificada.

Já para ilustrar o comportamento de uma lista foi elaborada uma lista alfabética dos alunos da turma. A atividade desplugada aconteceu da seguinte forma: Em um copo foi colocado o nome de todos os alunos e símbolos indicando remoção, na sala foi simulado um vetor com a quantidade dos alunos na sala. Cada aluno deveria sortear um colega e inseri-lo na lista de acordo com a ordem alfabética. Caso fosse necessário inserir um elemento em uma posição que já exista um colega era necessário causar o deslocamento a direita do elemento a última posição. O colega sorteado era o próximo a jogar. Caso o elemento de remoção fosse sorteado, o colega deveria eliminar outro e reorganizar a lista (A eliminação de um elemento requer o deslocamento à esquerda). $\mathrm{O}$ último a ficar na lista era bonificado.

Para ensinar sobre a lista encadeada com ponteiro para o próximo elemento. Dessa forma cada elemento da lista deve conter, além do dado propriamente dito, uma referência para o próximo elemento da lista. $\mathrm{Na}$ atividade desplugada, cada aluno deve criar uma lista encadeada onde o próximo será um ponteiro para a sua mãe, nela um ponteiro para avó, e assim até quarta geração.

A atividade desplugada sobre árvore binária, foi criada uma árvore genealógica, onde cada filho (nó) possui no máximo um pai e uma mãe. Cada aluno realizou a atividade de criar uma árvore genealógica de sua família até a terceira geração, no caso pais, avós (materno e paterno) e bisavós (materno e paterno).

\section{RESULTADOS E DISCUSSÃO}

Ao iniciar as aulas os alunos foram informados que já estavam com média 7, a notícia trouxe um impacto bem positivo, despertando grande interesse e curiosidade, mas, para garantir a nota ou melhorá-la, era necessário realizar as missões, se esforçar 
com dedicação de 1 hora de estudo por semana e ter um bom resultado na avaliação. Tais iniciativas eram necessárias para garantir melhor resultado na avaliação tradicional que corresponderia a $50 \%$ da nota, é válido ressaltar que caso às missões não atendessem às expectativas, a nota destas poderia ser diminuída. Diante do cenário proposto vários alunos se sentiram estimulados com a nova metodologia. As atividades de computação desplugada permitiram aos alunos vivenciar os conceitos e entender como os problemas são solucionados usando essas estruturas de dados. Após cada aula desplugada, foram realizadas atividades tradicionais e exercícios em laboratório computacional usando a linguagem C. Foi possível perceber que muitos alunos que continuaram frequentando a disciplina puderam ter um bom aproveitamento, pois entendiam às estruturas de dados com a simulação desplugada e depois exercitava seu funcionamento com a linguagem $\mathrm{C}$.

Durante às aulas alguns alunos apresentaram grandes dificuldades na codificação, por falta de base de lógica de programação, apresentando um grande déficit de conhecimentos técnicos básicos necessários para o bom andamento da disciplina. Foi identificado que $54 \%$ da turma não possuía conhecimentos prévios básicos para cursar estrutura de dados. Dessa maneira, foi realizado um teste com toda a turma para traçar um diagnóstico, e posteriormente elaborar um plano de estudos para cada aluno, a fim de nivelar a turma. Foi proposto uma rotina de estudo, indicação de vídeo aulas e exercícios. Uma monitora se voluntariou para auxiliar os alunos no estudo de programação. Mesmo com todo este apoio, 8 alunos desistiram da disciplina ao perceber que era necessário um esforço maior para revisão e estudo de conceitos básicos como estrutura sequencial, de repetição, vetor, registros e alocação dinâmica.

No entanto, para os que permaneceram na disciplina, a gamificação proporcionou uma aprendizagem divertida e significativa. A primeira missão desafiava os alunos a criarem uma atividade desplugada para ensino de recursividade. Dessa forma, eles precisavam estudar para entender e elaborar uma atividade, ou ainda buscar uma associação para apresentar como missão. A sala foi dividida em equipes que apresentaram seus trabalhos com êxito. Alguns dos trabalhos apresentados foram a Torre de Hanoi, Dinâmica Caça ao Tesouro usando recursividade e fatorial, Telefone sem fio recursivo, entre outros.
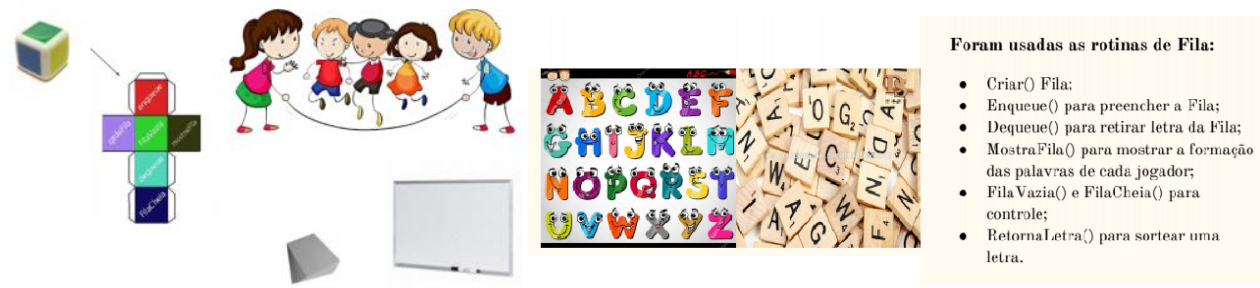

Figura 1 - Atividades elaboradas pelos alunos

Fonte: Autoras

Na segunda missão as equipes deveriam elaborar um jogo usando as regras da estrutura de dados fila, mas utilizando comandos da linguagem C. Algumas equipes tiveram dificuldade em inserir na atividade o uso de programação, mas os resultados foram positivos na versão final apresentada conforme ilustrado na Figura 1. Entre as soluções exitosas, destaca-se o jogo Pula Cordas com $\mathrm{C}$ e de palavras em filas, cujo objetivo era formar uma palavra com no mínimo 5 letras, estimulando o aprendizado dos vocábulos, usando uma fila de letras para cada jogador.

Na terceira missão os alunos precisavam identificar e demonstrar o uso de uma pilha em situações ou soluções para problemas cotidianos. Várias soluções foram apresentadas, entre elas: pote para guardar bolachas, que existe uma capacidade máxima, pilha de caixas de materiais diversos, onde existe a recomendação de número 
máximo para empilhamento, lista de comandos do pacote office para desfazer e refazer. Trazendo o entendimento sobre o uso e funcionamento da estrutura de dados.

$\mathrm{Na}$ quarta missão, que já fazia parte da segunda unidade, foi solicitada a elaboração de um jogo usando listas no computador ou com comandos em forma de blocos em EVA ou papel cartonado. Os alunos elaboraram várias soluções dentre elas destaca-se o Jogo de cartas Pife utilizando lista sequenciada e o Jogo "Lista sequencial na formação das palavras". Foi possível aprender de uma forma prática e divertida, usando analogia com a formação de palavras, compreender a ideia de uma lista sequencial com jogos criados por eles e entender como funcionam os comandos para esse tipo de lista.
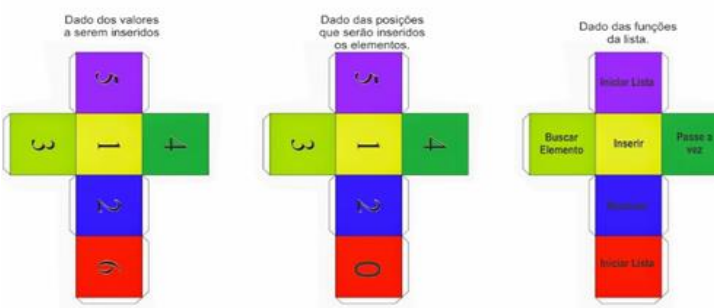

Inicia a lista, depois jogar:

- Dado 1 = o número que sair será inserido na

lista.

- Dado 2 = o número que sair será o local na lista.

- Dado 3 = escolha das funções.

Ganha quem encher e esvaziar a lista primeiro.

Figura 2 - Jogo elaborado por alunos

Fonte: Autoras

Na quinta missão era necessário criar uma atividade de computação desplugada usando lista simplesmente encadeada. A atividade apresentada que merece destaque, ilustrado na Figura 2, foi uma evolução do jogo Palavra em Fila, onde os alunos aprimoraram o jogo desenvolvido para fila e modificaram a regra, tornando mais desafiador e interessante pelo grau de liberdade de inserção e remoção de elementos que as funções de lista encadeada oferece. Na última missão o desafio foi criar árvore de decisão de forma criativa, onde as equipes apresentavam às árvores e explicavam o funcionamento.

Houve grande participação e interação dos alunos durante a disciplina, o que favoreceu a aprendizagem. Ao final da disciplina foi elaborado questionário e aplicado com a turma para realizar avaliação da proposta da metodologia utilizada. Esses resultados podem ser observados nos gráficos a seguir. 16 alunos responderam o questionário.

Quando questionados se a gamificação havia tornado o processo de aprendizagem mais efetivo e dinâmico, 93,8\% afirmaram que sim. O que pode ser visualizado no Gráfico 1.

\section{Gráfico 1 - Gamificação}

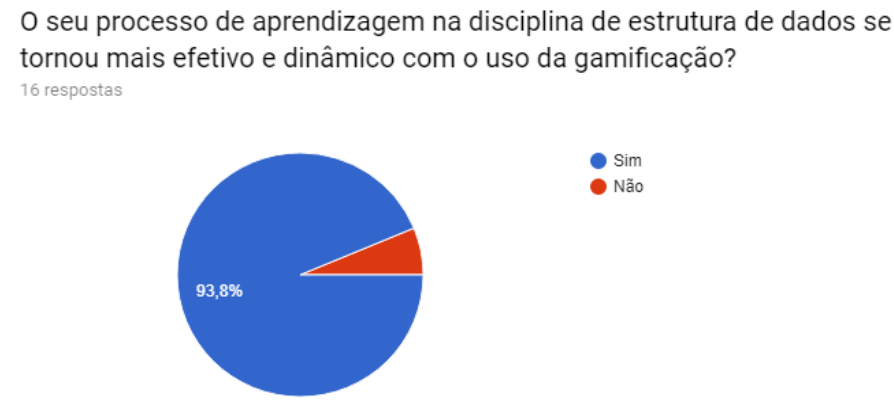

Fonte: Autoras 
Esse resultado demonstra que o uso da Gamificação contribuiu efetivamente para o processo de aprendizagem dos alunos. O que vai ao encontro do afirma Lee e Hammer (2011), que apontam que uma das vantagens da gamificação: é motivar os alunos a se envolverem com a sala de aula, incentivando-os a manterem uma aprendizagem para a vida toda. Os autores ainda defendem que a gamificação é o meio para tornar a educação divertida.

Quando questionados se teriam mais dificuldades em aprender Estrutura de Dados, sem o uso das metodologias Gamificação e Computação Desplugada, 68,8\% afirmaram que sim e 31,3\% disseram que não. (Gráfico 2)

\title{
Gráfico 2 - Gamificação e Computação Desplugada
}

\begin{abstract}
Sem o uso da gamificação e da computação desplugada você teria mais dificuldades em aprender os conceitos de Estrutura de Dados?
\end{abstract}

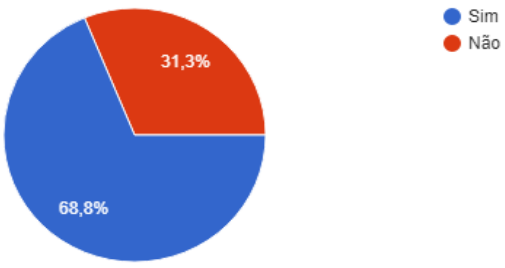

Fonte: Autoras

As respostas visualizadas no Gráfico 2 demonstram que o uso de metodologias diferenciadas pode proporcionar um ambiente mais significativo para os estudantes. Isso vai encontro dos resultados encontrados no trabalho Gincanas de Raciocínio Lógico (Dantas et al., 2013), onde a combinação da competitividade, contexto dos jogos (gamificação) e atividades lúdicas ofereceram melhorias no aprendizado e raciocínio lógico de alunos do Ensino Médio.

Quando questionados sobre a contribuição das missões/desafios propostos para serem desenvolvidos em equipe, 93,8\% afirmaram que sim. (Gráfico 3)

\section{Gráfico 3 - Missões/Desafios}
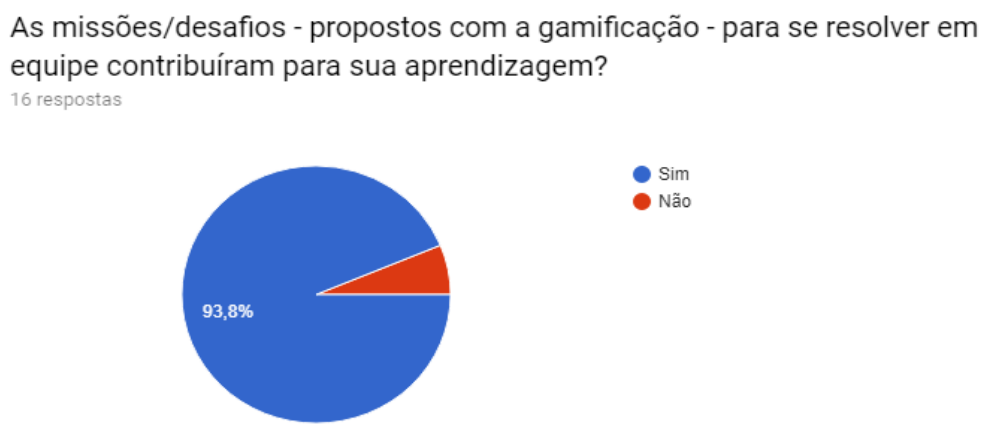

Fonte: Autoras

O resultado visualizado no Gráfico 3 reforça que a Gamificação pode proporcionar a aprendizagem colaborativa. É o que defende Brazil $(2017$, p.23) "o uso 
da gamificação é capaz de atingir resultados significativos na mobilização das pessoas para objetivos almejados". Dessa maneira, é notório que essa metodologia pode ser uma aposta para que os estudantes construam seu aprendizado através da coletividade, do trabalho em equipe.

O resultado final da disciplina pode ser visualizado na Tabela 2 que apresenta dados de alunos matriculados, desistentes e aprovados nos semestres anteriores, destacamos que apenas no semestre atual foi utilizada a gamificação e computação desplugada. Os dados foram obtidos do Sistema de Apoio a Gestão Escolar (SAGE) da instituição.

Tabela 2 - Histórico da disciplina de ED

\begin{tabular}{|c|c|c|c|c|}
\hline Semestre & Matriculados & Desistentes & Reprovados & Aprovados \\
\hline Atual (2018.1) & 26 & $12(46 \%)$ & $2(7,7 \%)$ & $12(46 \%)$ \\
\hline 2017.2 & 24 & $20(83 \%)$ & 0 & $4(17 \%)$ \\
\hline 2017.1 & 34 & $28(82 \%)$ & 0 & $6(18 \%)$ \\
\hline 2016.2 & 32 & $18(56 \%)$ & $4(13 \%)$ & $10(31 \%)$ \\
\hline 2016.1 & 27 & $10(37 \%)$ & $3(11 \%)$ & $14(52 \%)$ \\
\hline 2015.2 & 35 & $22(63 \%)$ & $6(17 \%)$ & $7(20 \%)$ \\
\hline
\end{tabular}

Fonte: SAGE

Destaca-se ainda que esta tabela foi apresentada no meio do semestre a fim de estimular os alunos a não desistissem da disciplina e que de fato tentassem passar, pois historicamente a disciplina não reprova tanto, o que de fato ocorre é a desistência dos alunos.

\section{CONSIDERAÇÕES FINAIS}

A proposta de reformulação da disciplina trouxe inicialmente inquietação às professoras que precisavam dinamizar sem perder o foco de ensinar e exercitar o uso das estruturas de dados usando uma linguagem de programação. Cada atividade desplugada usou entre 45 minutos a uma hora.

Com a experiência de gamificar a disciplina e ainda com o uso de atividades de computação desplugada foi possível contemplar os diferentes ritmos de aprendizagem de cada aluno, algo que não seria tão fácil de visualizar em uma metodologia tradicional.

Ao observarem o sistema de notas no primeiro dia de aula e verem que havia uma aprovação prévia (mesmo que condicionada ao seu desempenho na disciplina durante o semestre), os alunos relataram que isso minimizou o medo da reprovação e tornou a disciplina "mais leve". Entretanto, alguns alunos desistiram da disciplina, por diversos motivos, entre eles: trabalho, necessidade de maior dedicação para estudar a base, pouco tempo disponível para estudos no semestre, motivos pessoais e trancamento de curso.

Essa experiência mostrou que o uso da gamificação aliada a computação desplugada pode ressignificar a aprendizagem de disciplinas como Estrutura de Dados. 
Ao usar esse formato de ensino para disciplina foi percebido que os alunos "entraram no jogo" e mostraram engajamento em todas as atividades propostas.

\section{REFERÊNCIAS}

ANDRADE, d. et al. Proposta de Atividades para o Desenvolvimento do Pensamento Computacional no Ensino Fundamental, CBIE Trilha WIE 2013.

ANTUNES, Alexandre Rosot; FERNANDES, Eduardo Chaves. Proposta de Práticas em Computação Desplugada para Públicos de Altas Habilidades. 2015. $142 \mathrm{f}$. Trabalho de Conclusão de Curso - Bacharelado em Sistemas de Informação, Universidade Tecnológica Federal do Paraná. Curitiba, 2015.

ASCENCIO, Ana Fernanda Gomes; ARAÚJO, Graziela Santos de. Estruturas de Dados: algoritmos, análise da complexidade e implementações em JAVA e C/C++. São Paulo: Perarson Prentice Halt, v. 3, 2010.

BARBOSA, L. S.; FERNANDES, T. C., and Campos, A. M. (2011). Takkou: Uma ferramenta proposta ao ensino de algoritmos. In Anais do CSBC/XIX WEI.

BELL, Tim et al. Computer science unplugged: School students doing real computing without computers. The New Zealand Journal of Applied Computing and Information Technology, v. 13, n. 1, p. 20-29, 2009.

BRAZIL, André Luiz. Gamificação na produção colaborativa de conhecimento e informação. Orientadora: Sarita Albagli. 2017. 214 f. Tese (Doutorado em Ciência da Informação) - Escola de Comunicação, Universidade Federal do Rio de Janeiro, Programa de Pós-graduação em Ciência da Informação, Instituto Nacional de Informação em Ciência e Tecnologia, Rio de Janeiro, 2017.

CORREIA, A. L. et. al. (2015). Uso de avaliação por pares em disciplinas introdutórias de programação. In Anais do CSBC/XXIII WEI.

DANTAS, V., et al. (2013) . Uma metodologia para estimular o raciocínio lógico baseada na reflexão crítica e no uso de jogos digitais. Anais dos Workshops do Congresso Brasileiro de Informática na Educação. Vol. 2. No. 1.

FARDO, M. L. A gamificação aplicada em ambientes de aprendizagem. RENOTE. Revista Novas Tecnologias na Educação, v. 11, p. 1, 2013.

GOEHLE, G., Gamification and web-based homework, in: Primus 23.3 , 234-246, 2013 KOIVISTO, J.; HAMARI, J., Demographic Dif erences in perceived benefits gamification, in: Computers in Human Behavior, 35, p. 179-188, 2014.

LEE, J. J.; HAMMER, J. Gamification in Education: What , How , Why Bother? Academic Exchange Quarterly. v. 15, p. 1-5, 2011.

LI et. al (2013) "Engaging computer science students through gamification in an online social network based collaborative learning environment". International Journal of Information and Education Technology, v. 3, n. 1.

PAPERT, Seymour. A Máquina das Crianças: Repensando a Escola na Era da Informática. Trad. Sandra Costa. PortoAlegre:Artmed, 2008.

ROUSE, K., Gamification in science education: The relationship of educational games to motivation and achievement. 2013.

WING, J. (2006). Computational thinking. Communications of the ACM 49(3). ZICHERMANN, Gabe; CUNNINGHAM, Christopher. Gamification by Design. Implementing Game Mechanics in Web and Mobile Apps. Canada: O'ReillyMedia, 2011. 